\title{
Production of sugar alcohols from real biomass by supported platinum catalyst
}

\author{
Hirokazu Kobayashi ${ }^{\mathrm{a}}$, Yukiyasu Yamakoshi ${ }^{\mathrm{b}}$, Yuto Hosaka ${ }^{\mathrm{a}, \mathrm{c}}$, Mizuho Yabushita ${ }^{\mathrm{a}, \mathrm{c}}$, \\ Atsushi Fukuoka ${ }^{\mathrm{a}, *}$
}

${ }^{a}$ Catalysis Research Center, Hokkaido University, Kita 21 Nishi 10, Kita-ku, Sapporo, Hokkaido 001-0021, Japan.

${ }^{\mathrm{b}}$ Industrial Research Institute, Hokkaido Research Organization, Kita 19 Nishi 11, Kita-ku, Sapporo, Hokkaido 060-0819, Japan.

${ }^{\mathrm{c}}$ Graduate School of Chemical Sciences and Engineering, Hokkaido University, Kita 13 Nishi 8, Kita-ku, Sapporo, Hokkaido 060-8628, Japan.

*E-mail: fukuoka@ cat.hokudai.ac.jp, Fax: +81 117069139

\begin{abstract}
The influence of lignin and inorganic salts on the catalytic activity was studied in the hydrolytic hydrogenation of real biomass by a supported Pt catalyst. The direct conversion of raw silver grass by Pt/carbon catalyst under $\mathrm{H}_{2}$ pressure produced small amounts of sorbitol (2.8 wt \%), xylitol (7.3 $\mathrm{wt} \%$ ), and other sugar alcohols. It has been suggested that lignin reduces the reactivity of cellulose, as lignin exists together with cellulose in the biomass and both compounds are insoluble in water. Moreover, even weak bases drastically change the product distribution with more by-products such as EG and PG. Bases enhance the decomposition of sugar intermediates and sorbitol. The removal of lignin and inorganic salts by alkali-explosion and neutralization raises the contents of cellulose and hemicellulose, thus increasing the yields of sorbitol (13 wt\%) and xylitol (14 wt $\%)$ in the hydrolytic hydrogenation reactions.
\end{abstract}

Keywords: biomass, cellulose, hemicellulose, sorbitol, supported platinum catalyst, xylitol

\section{Introduction}

Catalytic conversion of lignocellulosic biomass has attracted great interest for the production of renewable chemicals and fuels, since this abundant material has been largely wasted $[1,2]$. Furthermore, the use of lignocellulose in chemical industry does not compete with food production, 
which is contrastive to current biorefinery using starch and molasses. Lignocellulose consists of cellulose, hemicellulose, and lignin, in which cellulose is a polymer of glucose and hemicellulose is a copolymer of various $\mathrm{C}_{5}$ and $\mathrm{C}_{6}$ sugars. Thus, the hydrolytic hydrogenation of the sugar polymers produces hexitols and pentitols (Figure 1), and these sugar alcohols are practically used as precursors to plastics, surfactants, and medicines as well as low-calorie and non-cariogenic sweeteners [2]. The annual productions of sorbitol and xylitol have already been $6.5 \times 10^{5}$ and $2-4 \times 10^{4}$ tons per year, respectively, although the current feedstock of sorbitol is starch. Hence, the hydrolytic hydrogenation of lignocellulosic biomass is an attractive issue for the next-generation biorefinery.

Cellulose conversion by heterogeneous catalysts has been intensively studied in the last several years [2], and it has been known that pure cellulose can be converted into sugar alcohols in good yields in one-pot by various supported metal catalysts under $\mathrm{H}_{2}$ pressure [3-27]. In the mechanism of this reaction, it has been found that the hydrolysis step is promoted by some supported metal catalysts [6,7] in addition to effect of hot-compressed water [28], and the hydrogenation is catalyzed by transition metals. In contrast, only a few reports have addressed the one-pot conversion of raw or less-treated biomass; arabitol [29] and xylitol [30, 31] have been synthesized from beet fiber and bleached birch kraft pulp, respectively. Furthermore, influence of various ingredients such as lignin and ionic compounds on this catalytic reaction has not yet been evaluated. Both acid and reduction catalysis can be affected by these components, and hydrolysis rate of cellulose is indeed declined by sulfate ions [32]. In this study, we conducted the conversion of real biomass and crystalline cellulose by a supported Pt catalyst (Pt/BP2000) to evaluate the effects of lignin and salts. Pt/BP2000 is one of the most active and durable catalysts for the conversion of pure cellulose [7]. Silver grass was mainly used as a substrate because this plant survives in cold climate unsuitable to food crops. Furthermore, silver grass moves nutrients such as $\mathrm{K}$ and $\mathrm{P}$ from the plant body to rhizomes before winter [33], and hence loss of the elements in soil by collecting the plant for biorefinery is small.

\section{Material and methods}

\subsection{Biomass materials}

Silver grass-1 is silver grass (Miscanthus sinensis) collected in summer in Kochi, and silver 
grass-2 is that mowed in winter in Nakashibetsu (Hokkaido). Other biomass used in this study was Amur silver grass (Miscanthus sacchariflorus) sampled in Nakashibetsu (Hokkaido) and wheat straw (Triticum aestivum) in Memuro (Hokkaido). These samples were coarsely ground using a cutter mill with a $3 \mathrm{~mm}$ screen (Horai MAC-0.75kW). Microcrystalline cellulose (Avicel, 1.02331.0500) was purchased from Merck.

\subsection{Pretreatment of biomass}

Five pretreatment methods were used in this study [34]; silver grass-1 was boiled in water at 373 $\mathrm{K}$ for $3 \mathrm{~h}$ (silver grass-1W), treated by the Soxhlet extraction using water for 3 days (silver grass-1S), or washed with $10 \mathrm{wt} \% \mathrm{HCl}$ aq. at $298 \mathrm{~K}$ for $3 \mathrm{~h}$ (silver grass-1H). Silver grass-2 was immersed in $1.4 \mathrm{wt} \% \mathrm{NaOH}$ at $298 \mathrm{~K}$ for $24 \mathrm{~h}$, and exploded after keeping the temperature at $463 \mathrm{~K}$ for $2 \mathrm{~min}$ (silver grass-2A). Silver grass-2A was neutralized with $\mathrm{HCl}$ at room temperature to adjust its $\mathrm{pH}$ to 3, and washed with water (silver grass-2AN). This set of alkali-explosion and neutralization is expressed as AN treatment hereafter, and also used for Amur silver grass and wheat straw (Amur silver grass-AN and wheat straw-AN, respectively).

\subsection{Composition analysis of biomass}

Elemental analysis of biomass was performed using energy dispersive X-ray spectroscopy (EDX; Shimadzu, EDX-720). The content of each sugar fraction in biomass was analyzed according to the literature (NREL, TP-510-42618 [35]). Biomass (300 mg) was stirred in $72 \% \mathrm{H}_{2} \mathrm{SO}_{4}$ aq. $(3.0 \mathrm{~mL})$ for $1 \mathrm{~h}$ at $303 \mathrm{~K}$. Water of $84 \mathrm{~mL}$ was added to the solution, and then agitated at $394 \mathrm{~K}$ for $1 \mathrm{~h}$ in a high-pressure reactor. The mixture was filtrated and the aqueous phase was analyzed by a high-performance liquid chromatography (HPLC; Shimadzu, LC10-ATVP, refractive index detector) equipped with a Shodex Sugar SH-1011 column $\left(\varnothing 8 \times 300 \mathrm{~mm}\right.$, mobile phase: water $0.5 \mathrm{~mL} \mathrm{~min}^{-1}$, $323 \mathrm{~K}$ ) after neutralizing with $\mathrm{CaCO}_{3}$ to $\mathrm{pH}$ 6. The amount of acid-insoluble lignin was determined from the weight difference before and after the combustion of solid residue at $848 \mathrm{~K}$. Crystallinity of biomass was analyzed by X-ray diffraction (XRD; Rigaku, MiniFlex, $\mathrm{Cu} \mathrm{K} \alpha$ ). 


\subsection{Preparation of catalysts}

$\mathrm{Pt}\left(\mathrm{NH}_{3}\right)_{2}\left(\mathrm{NO}_{2}\right)_{2}$ nitric acid solution (Tanaka Kikinzoku Kogyo, $138 \mu \mathrm{mol}$ ) was dropped into a mixture of carbon black BP2000 (Cabot, Black Pearls 2000, $2.0 \mathrm{~g}$ ) and water (20 mL), and the mixture was stirred for $16 \mathrm{~h}$. After drying in vacuo, the solid was treated with $\mathrm{H}_{2}\left(30 \mathrm{~mL} \mathrm{~min}{ }^{-1}\right)$ at $673 \mathrm{~K}$ for $2 \mathrm{~h}$. The prepared catalyst is denoted as $1.3 \mathrm{wt} \% \mathrm{Pt} / \mathrm{BP} 2000$.

\subsection{Hydrolytic hydrogenation of biomass}

Biomass (324 mg), Pt/BP2000 catalyst (200 mg, Pt $14 \mu \mathrm{g}$-atom), and water $(40 \mathrm{~mL})$ were transferred into a stainless steel high-pressure reactor (OM Lab-Tech, MMJ-100), and $5 \mathrm{MPa}$ of $\mathrm{H}_{2}$ was charged at room temperature. The reactor was heated to $463 \mathrm{~K}$ and kept at this temperature for $24 \mathrm{~h}$ with stirring at $600 \mathrm{rpm}$. Products were separated by centrifugation and decantation, and water-soluble products were analyzed by HPLC. The columns used in this work were a Phenomenex

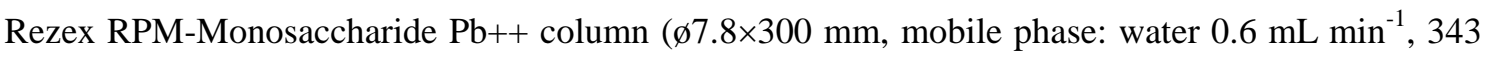
K) and a Shodex Sugar SH-1011 column $\left(\varnothing 8 \times 300 \mathrm{~mm}\right.$, mobile phase: water $\left.0.5 \mathrm{~mL} \mathrm{~min}^{-1}, 323 \mathrm{~K}\right)$. Product assignment was also checked by LC/MS (Thermo Fisher Scientific, LCQ-Fleet, APCI). The conversion of cellulose was determined by liquid-phase total organic carbon analysis (TOC; Shimadzu, TOC-V CSN) when we performed the model reactions using pure cellulose and salts. The formation of small amounts of gaseous products was excluded in this estimation.

\section{Results and discussion}

\subsection{Analysis of treated silver grasses}

Elemental compositions of silver grasses were analyzed by EDX as shown in Table 1. Si of 3.7 wt\% was detected in silver grass-1 as gramineous plants use silica for their frameworks (entry 1) [36]. Other ingredients were $\mathrm{K}(1.0 \mathrm{wt} \%), \mathrm{Ca}(0.14), \mathrm{P}(0.13), \mathrm{S}(0.09), \mathrm{Fe}(0.03)$, and $\mathrm{Cl}(0.02) . \mathrm{K}, \mathrm{P}$, and $\mathrm{Cl}$ were almost completely removed by boiling in water, and the amounts of $\mathrm{Si}$ and $\mathrm{S}$ decreased by half (silver grass-1W, entry 2). However, the contents of $\mathrm{Ca}$ and $\mathrm{Fe}$ were unchanged. The Soxhlet extraction reduced $\mathrm{Ca}$ to $0.03 \mathrm{wt} \%$ in addition to the effect of boiling water (silver grass-1S, 
entry 3). The $\mathrm{HCl}$ treatment provided a similar result to that of the Soxhlet extraction, but $\mathrm{Si}$ remained unchanged at $3.4 \mathrm{wt} \%$ (silver grass-1H, entry 4). The amounts of $\mathrm{K}(0.08)$ and $\mathrm{P}(0.01)$ in silver grass-2, collected in winter, were significantly lower than those in silver grass-1 (entry 5) mowed in summer. The AN treatment for silver grass-2 (entry 6) had a similar effect to that of the Soxhlet extraction (entry 3). It is thus shown that $\mathrm{K}$ and $\mathrm{P}$ are eliminated completely and the $\mathrm{S}$ content is declined in these four treatments.

The NREL/TP-510-42618 method [35] was used to determine the contents of sugar polymers and lignin. Silver grass-1 had cellulose (34 wt \%), hemicellulose (19 wt \%), and lignin (26 wt $\%$ ) (Table 2 , entry 7), and the hemicellulose consisted of xylan $16 \mathrm{wt} \%$, arabinan $2.6 \mathrm{wt} \%$, and negligible amounts of other sugar residues. The boiling treatment slightly increased cellulose ( $42 \mathrm{wt} \%)$ and hemicellulose (24 wt $\%$ ), whereas lignin was reduced (18 wt $\%$ ) (Table 2, entry 8 ). The alkali-explosion for silver grass-2 (entries 9, 10) gave a similar effect to that by the boiling for silver grass-1 (entries 7, 8), and combination with neutralization using $\mathrm{HCl}$, the AN treatment, obviously decreased the amount of lignin from 21 to $11 \mathrm{wt} \%$ in addition to the increase of cellulose content (38 to $58 \mathrm{wt} \%$ ) (entries 9, 11). Hence, the AN treatment is more effective than the boiling and the single alkali-explosion to remove useless ingredients. Although the loss of carbohydrates during pretreatments sometimes comes to an issue, $87 \mathrm{wt} \%$ of carbohydrates (> $95 \mathrm{wt} \%$ of cellulose, 74 wt $\%$ of hemicellulose) remained in the AN treatment of silver grass-2 (not shown in Table 2). The constituents of Amur silver grass-AN and wheat straw-AN were similar to those of silver grass-2AN (entries 12, 13).

XRD patterns of silver grass-1, 2, and 2AN are shown in Figure 2. All of them provided similar diffraction peaks of cellulose I at $16^{\circ}, 23^{\circ}$, and $35^{\circ}$, and the crystallinity indexes were $55-60 \%$ for the samples. Accordingly, cellulose I crystals was stable even in the AN treatment at $463 \mathrm{~K}$. Although it is known that $\mathrm{NaOH}$ aq. (> $8 \mathrm{wt} \%$ ) transforms cellulose I to cellulose II [37], the concentration of $\mathrm{NaOH}$ used in the $\mathrm{AN}$ treatment in this work was too low (1.4 wt\%) to cause it.

\subsection{Hydrolytic hydrogenation of biomass}

Pristine and pretreated silver grass powders were subjected to the hydrolytic hydrogenation by 
$1.3 \mathrm{wt} \% \mathrm{Pt} / \mathrm{BP} 2000$ catalyst at $463 \mathrm{~K}$ for $24 \mathrm{~h}$. Silver grass-1 gave sorbitol in $2.8 \mathrm{wt} \%$ yield based on the weight of the substrate and xylitol in $7.3 \mathrm{wt} \%$ yield (Table 3, entry 14), and identified major by-products were ethylene glycol (EG; $2.0 \mathrm{wt} \%)$ and propylene glycol (PG; $4.0 \mathrm{wt} \%)$. Conversions of cellulose and hemicellulose were not determined in this case, as the substrate consists of many ingredients. The dissolution amount of the sample was $57 \mathrm{wt} \%$, containing both the conversion of carbohydrates and the dissolution of any components. Silver grass-1W, the boiled sample, afforded xylitol and arabitol in $16 \mathrm{wt} \%$ and $4 \mathrm{wt} \%$, respectively, and the total yield of the pentitols corresponds to $72 \% \mathrm{C}$ based on containing hemicellulose (entry 15 ). The yield of sorbitol almost did not change ( $4.0 \mathrm{wt} \% ; 8.6 \% \mathrm{C}$ based on containing cellulose), and those of EG (1.3 wt $\%)$ and PG (2.1 wt $\%$ ) decreased similarly. The Soxhlet extraction and $\mathrm{HCl}$ pretreatments also increased the yield of xylitol (entries 16, 17), suggesting that xylitol was produced in good yields by reducing the amounts of metal cations, $\mathrm{P}$, and S. Phosphorus and sulfur compounds are typical poisons to hydrogenation catalysts. It is not probable that metal cations directly inhibit the hydrolytic hydrogenation, but counter anions may promote side-reactions or slow down the hydrolysis step as shown in section 3.3. Meanwhile, the catalyst was tolerant to a small amount of $\mathrm{SiO}_{2}$ as the yield of xylitol was independent of the content of $\mathrm{Si}$ in the range of 1.5-3.4 wt\%. The yields of sorbitol were only 3.5-4.8 wt $\%$ also in these cases. A control experiment using pure crystalline cellulose provided a significantly higher yield of sorbitol [39 wt\% (35\%C)] under the same reaction conditions (Table 4 entry 24), indicating the presence of inhibitors for the reaction of cellulose in the silver grass. Since cellulose is almost insoluble even in hot-compressed water at $<590 \mathrm{~K}$ [38], a presumable reason would be coexistence of lignin (18 wt\% in silver grass-1W) that prevents the depolymerization of cellulose.

A prospective strategy to convert cellulose in real biomass is the removal of lignin. Therefore, silver grass-2AN was subjected to the hydrolytic hydrogenation as this substance had a less amount of lignin (11 wt \%). Silver grass-2AN afforded the highest yield of sorbitol (13 wt $\%$, corresponding to $20 \% \mathrm{C}$ based on cellulose, entry 19) among treated silver grasses, implying that the removal of lignin made cellulose reactive. The yield of xylitol was improved (14 wt \%, $45 \% \mathrm{C})$ and those of EG and PG were kept low (0.9 wt $\%, 1.5 \mathrm{wt} \%$, respectively) by the AN pretreatment. Silver grass-2A 
was also tested in the hydrolytic hydrogenation, but negligible amounts of sorbitol and xylitol were formed (entry 18). Instead, EG of $4.5 \mathrm{wt} \%$ and PG of $4.7 \mathrm{wt} \%$ were produced due to the contamination of base, the detailed effect of which is discussed in section 3.3. Thus, silver grass-2AN was chosen to study the time course of this reaction (Figure 3). The amount of sorbitol smoothly increased to $13 \mathrm{wt} \%(20 \% \mathrm{C})$ over $24 \mathrm{~h}$, whereas that of xylitol was maximized at $4 \mathrm{~h}(19$ $\mathrm{wt} \%, 60 \% \mathrm{C}$ ) and gradually decreased. The quicker formation of xylitol is due to higher reactivity of hemicellulose, as the rate-determining step is the hydrolysis of sugar polymers [7]. Reuse experiments of Pt/BP2000 were performed in the reaction of silver grass-2AN (Table 3, entries 19-21), in which the yields of sorbitol and xylitol obviously dropped in the second run (entry 20). Since Pt/BP2000 is reusable in the reaction of pure cellulose [7], the reduction of yield may be ascribed to some ingredients such as lignin (7 wt \%), sulfur $(0.03 \mathrm{wt} \%)$, or remaining basic compounds. This problem has not been overcome by changing catalyst components. Although the active metals for the hydrolytic hydrogenation are $\mathrm{Ru}$ and $\mathrm{Ni}$ in addition to $\mathrm{Pt}$, it is known that $\mathrm{Ru}$ is very sensitive to sulfides [39]. A Ni/KB catalyst working for the reaction of pure cellulose did not give a good yield of xylitol even in the reaction of purified hemicellulose (Table 4, entries 31, 32). In addition, carbon is the best support in terms of tolerance to hot water and selectivity for sugar alcohols [7].

The AN treatment was applied to other biomass; the yields of sorbitol and xylitol were $17 \mathrm{wt} \%$ $(25 \% \mathrm{C})$ and $16 \mathrm{wt} \%(50 \% \mathrm{C})$, respectively, in the reaction of Amur silver grass-AN (entry 22). Likewise, wheat straw-AN gave $12 \mathrm{wt} \%(20 \% \mathrm{C}$ ) yield of sorbitol and $15 \mathrm{wt} \%$ (49\%C) yield of xylitol (entry 23). The AN pretreatment is useful to increase the yield of sorbitol in the hydrolytic hydrogenation of real biomass.

\subsection{Influences of salts estimated in model reactions}

We have observed that washing of biomass to remove inorganic salts is effective to increase the yields of sugar alcohols. Thus, model reactions using microcrystalline cellulose were conducted to clearly evaluate the effects of inorganic salts (Table 4). Pt/BP2000 catalyst transformed cellulose to sorbitol (35\%C yield) and mannitol $(3.7 \% \mathrm{C})$, and the formation of EG $(0.4 \% \mathrm{C})$ and PG $(0.4 \% \mathrm{C})$ 
were suppressed (entry 24$)$. Other products were sorbitan $(2.7 \% \mathrm{C})$, hexanetetrol $(0.3 \% \mathrm{C})$, erythritol $(1.0 \% \mathrm{C})$, glycerol $(0.5 \% \mathrm{C})$, and unidentified ones $(6 \% \mathrm{C})$. The yield of sorbitol dramatically reduced $(0.3 \% \mathrm{C})$ by the addition of $\mathrm{CaCO}_{3}$ regardless of fair conversion of cellulose (38\%) (entry 25). Note that hydrolysis of cellulose still takes place in the absence of protons by adding the base. Even in the non-catalytic reaction, water molecules may directly attack glycosidic bonds at high temperatures [28]. In contrast, the yields of EG and PG increased to $4.3 \% \mathrm{C}$ and $5.2 \% \mathrm{C}$, respectively. The reaction of cellulose catalyzed by Ru/BP2000 also showed almost the same effect by adding $\mathrm{CaCO}_{3}$ (entries 29, 30), suggesting that the drastic change of product distribution commonly happens by the salt. In the presence of $\mathrm{CaSO}_{4}$, the yield of sorbitol given by Pt/BP2000 was as high as $25 \%$ C, but neither EG nor PG increased (entry 26). In this case, the conversion of cellulose $(33 \%)$ was lower than that $(50 \%)$ in the absence of the salt due to the deceleration of hydrolysis by $\mathrm{SO}_{4}{ }^{2-}$ [32]. A similar phenomenon was observed by adding $\mathrm{NaHCO}_{3}$ and $\mathrm{Na}_{2} \mathrm{SO}_{4}$. $\mathrm{NaHCO}_{3}$ reduced the yield of sorbitol to $1.0 \% \mathrm{C}$ but increased EG and PG to $14 \% \mathrm{C}$ in total (entry 27), whereas $\mathrm{Na}_{2} \mathrm{SO}_{4}$ just decreased the conversion of cellulose to $28 \%$ (entry 28). These results suggest that the basic anions $\left(\mathrm{CO}_{3}{ }^{2-}, \mathrm{HCO}_{3}{ }^{-}\right)$drastically shift the products distribution from sorbitol to by-products. It has been reported that Ni catalysts supported on basic supports convert cellulose to EG and PG [40, 41]. The reaction of raw silver grass-1 gave low yields of sugar alcohols, but the amounts of EG and PG were larger than those in the reaction of the pretreated samples (Table 3, entries 14-17). The reason for this difference might be due to the presence of basic compounds in the raw biomass. Consequently, even weak bases such as $\mathrm{NaHCO}_{3}$ need to be removed for the production of sorbitol.

We propose that bases enhance both the side-reactions of sugar intermediates in the reaction of cellulose and promote the decomposition of sorbitol [42] (Figure 4). For the former point, it is known that bases catalyze the isomerization and retro-aldol reactions of glucose. For the latter, control experiments for the degradation of sorbitol were performed with Pt/BP2000 or $\mathrm{CaCO}_{3}$ catalysts. Pt/BP2000 decomposed sorbitol under the reaction conditions (37\% conversion, entry 33), but neither EG nor PG were formed (total $0.4 \% \mathrm{C}$ yield). By adding $\mathrm{CaCO}_{3}$ to this system, conversion of sorbitol increased to $95 \%$, and yields of EG and PG were remarkably raised (total 
$30 \% \mathrm{C}$, entry 34). In contrast, $\mathrm{CaCO}_{3}$ did not transform sorbitol in the absence of Pt catalyst (entry 35), showing that metal and base catalysts synergistically decompose sorbitol. Thus, we speculate that metal catalysts cause both dehydrogenation of sorbitol and hydrogenation of sugars in a chemical equilibrium, and that the sugars undergo base-catalyzed reactions. A similar mechanism has been proposed for the conversion of xylitol to EG and PG [42]. Pt also degrades sugars [43], but bases are significantly more active as even weak bases drastically change the product selectivity.

\section{Conclusions}

The direct conversion of raw silver grass by a carbon-supported Pt catalyst under $\mathrm{H}_{2}$ pressure produced small amounts of sorbitol (2.8 wt $\%)$, xylitol (7.3 wt $\%)$, and other sugar alcohols. It has been suggested that lignin reduces the reactivity of cellulose, as lignin presents together with cellulose and both compounds are insoluble in water. Moreover, even weak bases drastically changes the main products from sugar alcohols to by-products such as EG and PG. The major effect of bases is the decomposition of sugar intermediates and sorbitol. The removal of these ingredients by alkali-explosion and neutralization, condensing cellulose and hemicellulose at the same time, increased the yields of sorbitol (13 wt $\%)$ and xylitol (14 wt $\%)$. Simple boiling treatment is not suitable for the synthesis of sorbitol, but effective for the production of xylitol, as lignin largely remains.

\section{Acknowledgements}

We would like to thank Prof. Toshihiko Yamada for supplying silver grass-1. This work was supported by a Grant-in-Aid for Scientific Research (KAKENHI, 20226016).

\section{References}

[1] C.O. Tuck, E. Pérez, I.T. Horváth, R.A. Sheldon, M. Poliakoff, Science 337 (2012) 695-699.

[2] H. Kobayashi, A. Fukuoka, Green Chem. 15 (2013) 1740-1763.

[3] A. Fukuoka, P.L. Dhepe, Angew. Chem. Int. Ed. 45 (2006) 5161-5163.

[4] C. Luo, S. Wang, H. Liu, Angew. Chem. Int. Ed. 46 (2007) 7636-7639. 
[5] W. Deng, X. Tan, W. Fang, Q. Zhang, Y. Wang, Catal. Lett. 133 (2009) 167-174.

[6] V. Jollet, F. Chambon, F. Rataboul, A. Cabiac, C. Pinel, E. Guillon, N. Essayem, Green Chem. 11 (2009) 2052-2060.

[7] H. Kobayashi, Y. Ito, T. Komanoya, Y. Hosaka, P. L. Dhepe, K. Kasai, K. Hara, A. Fukuoka, Green Chem. 13 (2011) 326-333.

[8] R.M. Ravenelle, F.Z. Diallo, J.C. Crittenden, C. Sievers, ChemCatChem 4 (2012) 492-494.

[9] J. Geboers, S. Van de Vyver, K. Carpentier, P. Jacobs, B. Sels, Green Chem. 13 (2011) 2167-2174.

[10] M. Liu, W. Deng, Q. Zhang, Y. Wang, Y. Wang, Chem. Commun. 47 (2011) 9717-9719.

[11] H. Kobayashi, H. Matsuhashi, T. Komanoya, K. Hara, A. Fukuoka, Chem. Commun. 47 (2011) 2366-2368.

[12] J. Pang, A. Wang, M. Zheng, Y. Zhang, Y. Huang, X. Chen, T. Zhang, Green Chem. 14 (2012) 614-617.

[13] T. Deng, H. Liu, Green Chem. 15 (2013) 116-124.

[14] J.W. Han, H. Lee, Catal. Commun. 19 (2012) 115-118.

[15] D. Reyes-Luyanda, J. Flores-Cruz, P.J. Morales-Pérez, L.G. Encarnación-Gómez, F. Shi, P.M. Voyles, N. Cardona-Martínez, Top. Catal. 55 (2012) 148-161.

[16] L.-N. Ding, A.-Q. Wang, M.-Y. Zheng, T. Zhang, ChemSusChem 3 (2010) 818-821.

[17] P. Yang, H. Kobayashi, K. Hara, A. Fukuoka, ChemSusChem 5 (2012) 920-926.

[18] S. Van de Vyver, J. Geboers, M. Dusselier, H. Schepers, T. Vosch, L. Zhang, G. Van Tendeloo, P.A. Jacobs, B.F. Sels, ChemSusChem 3 (2010) 698-701.

[19] S. Van de Vyver, J. Geboers, W. Schutyser, M. Dusselier, P. Eloy, E. Dornez, J.W. Seo, C.M. Courtin, E.M. Gaigneaux, P.A. Jacobs, B.F. Sels, ChemSusChem 5 (2012) 1549-1558.

[20] G. Liang, H. Cheng, W. Li, L. He, Y. Yu, F. Zhao, Green Chem. 14 (2012) 2146-2149.

[21] J. Geboers, S. Van de Vyver, K. Carpentier, K. de Blochouse, P. Jacobs, B. Sels, Chem. Commun. 46 (2010) 3577-3579.

[22] R. Palkovits, K. Tajvidi, A.M. Ruppert, J. Procelewska, Chem. Commun. 47 (2011) 576-578.

[23] Y. Zhu, Z.N. Kong, L.P. Stubbs, H. Lin, S. Shen, E.V. Anslyn, J.A. Maguire, ChemSusChem 3 
(2010) 67-70.

[24] I.A. Ignatyev, C. Van Doorslaer, P.G.N. Mertens, K. Binnemans, D.E. De Vos, ChemSusChem 3 (2010) 91-96.

[25] J. Geboers, S. Van de Vyver, K. Carpentier, P. Jacobs, B. Sels, Chem. Commun. 47 (2011) $5590-5592$.

[26] Y. Ogasawara, S. Itagaki, K. Yamaguchi, N. Mizuno, ChemSusChem 4 (2011) 519-525.

[27] J. Hilgert, N. Meine, R. Rinaldi, F. Schüth, Energy Environ. Sci. 6 (2013) 92-96.

[28] O. Bobleter, Prog. Polym. Sci. 19 (1994) 797-841.

[29] S.K. Guha, H. Kobayashi, K. Hara, H. Kikuchi, T. Aritsuka, A. Fukuoka, Catal. Commun. 12 (2011) 980-983.

[30] M. Käldström, N. Kumar, D.Y. Murzin, Catal. Today 167 (2011) 91-95.

[31] M. Käldström, N. Kumar, M. Tenho, M.V. Mokeev, Y.E. Moskalenko, D.Y. Murzin, ACS Catal. 2 (2012) 1381-1393.

[32] H. Kobayashi, M. Yabushita, T. Komanoya, K. Hara, I. Fujita, A. Fukuoka, ACS Catal. 3 (2013) 581-587.

[33] M. Himken, J. Lammel, D. Neukirchen, U. Czypionka-Krause, H.-W. Olfs, Plant Soil 189 (1997) 117-126.

[34] M.J. Taherzadeh, K. Karimi, Int. J. Mol. Sci. 9 (2008) 1621-1651.

[35] A. Sluiter, B. Hames, R. Ruiz, C. Scarlata, J. Sluiter, D. Templeton, D. Crocker, NREL/TP-510-42618 (2011). http://www.nrel.gov/biomass/pdfs/42618.pdf.

[36] J.F. Ma, N. Yamaji, Trends Plant Sci. 11 (2006) 392-397.

[37] E. Dinand, M. Vignon, H. Chanzy, L. Heux, Cellulose 9 (2002) 7-18.

[38] S. Deguchi, K. Tsujii, K. Horikoshi, Chem. Commun. (2006) 3293-3295.

[39] C.H. Bartholomew, Appl. Catal. A: Gen. 212 (2001) 16-60.

[40] X. Wang, L. Meng, F. Wu, Y. Jiang, L. Wang, X. Mu, Green Chem. 14 (2012) 758-765.

[41] X. Wang, F. Wu, S. Yao, Y. Jiang, J. Guan, X. Mu, Chem. Lett. 41 (2012) 476-478.

[42] J. Sun, H. Liu, Green Chem. 13 (2011) 135-142.

[43] Y. Kanie, K. Akiyama, M. Iwamoto, Catal. Today 178 (2011) 58-63. 
Tables

Table 1 EDX analysis of biomass.

\begin{tabular}{lllllllll}
\hline & & \multicolumn{9}{l}{ Element $/ \mathrm{wt} \%$} & & & & & \\
\cline { 3 - 10 } Entry & Biomass & $\mathrm{K}$ & $\mathrm{Ca}$ & $\mathrm{Fe}$ & $\mathrm{Si}$ & $\mathrm{P}$ & $\mathrm{S}$ & $\mathrm{Cl}$ \\
\hline 1 & Silver grass-1 & 1.0 & 0.14 & 0.03 & 3.7 & 0.13 & 0.09 & 0.02 \\
2 & Silver grass-1W & 0.04 & 0.15 & 0.02 & 1.7 & 0.01 & 0.05 & n.d. $^{\text {a }}$ \\
3 & Silver grass-1S & n.d. $^{\mathrm{a}}$ & 0.03 & 0.03 & 1.5 & n.d. $^{\mathrm{a}}$ & 0.04 & n.d. $^{\mathrm{a}}$ \\
4 & Silver grass-1H & n.d. $^{\mathrm{a}}$ & n.d. $^{\mathrm{a}}$ & 0.02 & 3.4 & n.d. $^{\mathrm{a}}$ & 0.04 & 0.01 \\
5 & Silver grass-2 & 0.08 & 0.21 & 0.01 & 7.7 & 0.01 & 0.04 & 0.03 \\
6 & Silver grass-2AN & n.d. $^{\mathrm{a}}$ & 0.03 & 0.01 & 2.2 & n.d. $^{\mathrm{a}}$ & 0.03 & 0.10 \\
\hline
\end{tabular}

${ }^{\mathrm{a}}$ Not detected.

Table 2 Dry-basis composition of biomass.

\begin{tabular}{lllllr}
\hline \multirow{2}{*}{ Entry } & \multirow{2}{*}{ Biomass } & \multicolumn{3}{l}{ Ingredient $/ \mathrm{wt} \%$} & Acid-insoluble \\
\cline { 3 - 6 } & & $\begin{array}{l}\text { Glucan } \\
\text { (cellulose) }\end{array}$ & $\begin{array}{l}\mathrm{C}_{5} \text { sugar polymers } \\
\text { (hemicellulose) }\end{array}$ & $\begin{array}{l}\text { Acmin } \\
\text { lignin }\end{array}$ & \\
\hline 7 & Silver grass-1 & 34 & 19 & 26 & 21 \\
8 & Silver grass-1W & 42 & 24 & 18 & 16 \\
9 & Silver grass-2 & 38 & 24 & 21 & 17 \\
10 & Silver grass-2A & 50 & 25 & 17 & 8 \\
11 & Silver grass-2AN & 58 & 27 & 11 & 4 \\
12 & Amur silver grass-AN & 62 & 27 & 7 & 4 \\
13 & Wheat straw-AN & 55 & 27 & 14 & 4 \\
\hline
\end{tabular}

Table 3 Hydrolytic hydrogenation of biomass over Pt/BP2000 catalyst.

\begin{tabular}{|c|c|c|c|c|c|c|c|c|}
\hline \multirow[b]{2}{*}{ Entry } & \multirow[b]{2}{*}{ Substrate } & \multicolumn{7}{|c|}{ Yield $^{\mathrm{a}} / \mathrm{wt} \%$ based on dried substrate } \\
\hline & & Sor & Man & Xyl & Ara & & EG & PG \\
\hline 14 & Silver grass-1 & $2.8(7.4)^{b}$ & $0 \quad(0)^{b}$ & $7.3(33)^{\mathrm{c}}$ & 3.9 & $18)^{\mathrm{c}}$ & 2.0 & 4.0 \\
\hline 15 & Silver grass-1W & $4.0(8.6)^{b}$ & $0 \quad(0)^{\mathrm{b}}$ & $16(57)^{\mathrm{c}}$ & 4.0 & $(15)^{\mathrm{c}}$ & 1.3 & 2.1 \\
\hline 16 & Silver grass-1S & 4.8 & 0 & 15 & 3.5 & & 1.3 & 2.4 \\
\hline 17 & Silver grass-1H & 3.5 & 0 & 13 & 3.5 & & 1.1 & 2.6 \\
\hline 18 & Silver grass-2A & $0.4(0.7)^{\mathrm{b}}$ & $0 \quad(0)^{\mathrm{b}}$ & $1.4(4.9)^{\mathrm{c}}$ & 0.9 & $(3.1)^{\mathrm{c}}$ & 4.5 & 4.7 \\
\hline 19 & Silver grass-2AN & $13(20)^{\mathrm{b}}$ & $1.9(2.9)^{\mathrm{b}}$ & $14(45)^{\mathrm{c}}$ & 2.0 & $(6.2)^{\mathrm{c}}$ & 0.9 & 1.5 \\
\hline $20^{\mathrm{d}}$ & Silver grass-2AN & $4.6(6.9)^{\mathrm{b}}$ & $2.0(3.0)^{\mathrm{b}}$ & $6.1(28)^{\mathrm{c}}$ & 0 & $(0)^{c^{\prime}}$ & 2.9 & 5.4 \\
\hline $21^{\mathrm{d}}$ & Silver grass-2AN & $2.6(3.9)^{\mathrm{b}}$ & $1.6(2.4)^{\mathrm{b}}$ & $5.7(27)^{\mathrm{c}}$ & 0 & $(0)^{\mathrm{c}}$ & 3.0 & 5.7 \\
\hline 22 & Amur silver grass-AN & $17(25)^{\mathrm{b}}$ & $2.5(4.0)^{\mathrm{b}}$ & $16(50)^{\mathrm{c}}$ & 2.6 & $(8.2)^{\mathrm{c}}$ & 1.1 & 1.8 \\
\hline 23 & Wheat straw-AN & $12(20)^{\mathrm{b}}$ & $2.0(3.2)^{\mathrm{b}}$ & $15(49)^{\mathrm{c}}$ & 2.0 & $(6.4)^{\mathrm{c}}$ & 0.8 & 1.3 \\
\hline
\end{tabular}

Reaction conditions: $1.3 \mathrm{wt} \% \mathrm{Pt} / \mathrm{BP} 2000200 \mathrm{mg}$, substrate $320 \mathrm{mg}$ (dry basis), water $40 \mathrm{~mL}, p\left(\mathrm{H}_{2}\right) 5 \mathrm{MPa}, 463 \mathrm{~K}, 24$ h. ${ }^{a}$ Sor: sorbitol; Man: mannitol; Xyl: xylitol; Ara: arabitol; EG: ethylene glycol; PG: propylene glycol. ${ }^{\text {b } \% C ~ b a s e d ~}$ on containing cellulose. ${ }^{\mathrm{c}} \% \mathrm{C}$ based on containing hemicellulose. ${ }^{\mathrm{d}}$ A reuse experiment using the residue of the experiment of the previous entry number and fresh substrate of $320 \mathrm{mg}$. 
Table 4 Control experiments for hydrolytic hydrogenation.

\begin{tabular}{|c|c|c|c|c|c|c|c|c|c|c|c|}
\hline \multirow[b]{2}{*}{ Entry } & \multirow[b]{2}{*}{ Catalyst } & \multirow[b]{2}{*}{ Additive } & \multirow[b]{2}{*}{ Substrate } & \multirow{2}{*}{$\begin{array}{l}\text { Conv. } \\
1 \%\end{array}$} & \multicolumn{7}{|c|}{ Yield $^{\mathrm{a}} / \% \mathrm{C}$} \\
\hline & & & & & Sor & Man & Xyl & Ara & EG & PG & Others \\
\hline 24 & $\mathrm{Pt} / \mathrm{BP} 2000$ & None & Cellulose $^{\mathrm{d}}$ & 50 & 35 & 3.7 & - & - & 0.4 & 0.4 & 11 \\
\hline 25 & $\mathrm{Pt} / \mathrm{BP} 2000$ & $\mathrm{CaCO}_{3}$ & Cellulose $^{\mathrm{d}}$ & 38 & 0.3 & 0.3 & - & - & 4.3 & 5.2 & 28 \\
\hline 26 & $\mathrm{Pt} / \mathrm{BP} 2000$ & $\mathrm{CaSO}_{4} \cdot 0.5 \mathrm{H}_{2} \mathrm{O}$ & Cellulose $^{\mathrm{d}}$ & 33 & 25 & 2.6 & - & - & 0.4 & 0.3 & 5 \\
\hline 27 & $\mathrm{Pt} / \mathrm{BP} 2000$ & $\mathrm{NaHCO}_{3}$ & Cellulose $^{\mathrm{d}}$ & 42 & 1.0 & 0.4 & - & - & 5.5 & 8.5 & 27 \\
\hline 28 & $\mathrm{Pt} / \mathrm{BP} 2000$ & $\mathrm{Na}_{2} \mathrm{SO}_{4}$ & Cellulose $^{\mathrm{d}}$ & 29 & 16 & 2.8 & - & - & 0.5 & 0.4 & 9 \\
\hline 29 & Ru/BP2000 & None & Cellulose $^{\mathrm{d}}$ & 47 & 18 & 2.7 & - & - & 1.1 & 2.7 & 23 \\
\hline 30 & Ru/BP2000 & $\mathrm{CaCO}_{3}$ & Cellulose $^{\mathrm{d}}$ & 48 & 0.1 & 0 & - & - & 6.2 & 6.1 & 36 \\
\hline $31^{\mathrm{b}}$ & Pt/BP2000 & None & Hemicellulose $\mathrm{e}^{\mathrm{e}}$ & - & - & - & $96^{\mathrm{h}}$ & $61^{\mathrm{i}}$ & 0.4 & 1.6 & - \\
\hline $32^{\mathrm{b}}$ & $\mathrm{Ni} / \mathrm{KB}^{\mathrm{c}}$ & None & Hemicellulose $\mathrm{e}^{\mathrm{e}}$ & - & - & - & $30^{\mathrm{h}}$ & $46^{\mathrm{i}}$ & 1.9 & 10 & - \\
\hline 33 & $\mathrm{Pt} / \mathrm{BP} 2000$ & None & Sorbitol $^{\mathrm{f}}$ & $37^{\mathrm{g}}$ & - & 2.5 & - & - & 0.1 & 0.3 & 34 \\
\hline 34 & $\mathrm{Pt} / \mathrm{BP} 2000$ & $\mathrm{CaCO}_{3}$ & Sorbitol $^{f}$ & $95^{\mathrm{g}}$ & - & 1.3 & - & - & 12 & 18 & 64 \\
\hline 35 & None & $\mathrm{CaCO}_{3}$ & Sorbitol $^{f}$ & $1^{\mathrm{g}}$ & - & 0.6 & - & - & 0 & 0 & 0 \\
\hline
\end{tabular}

Reaction conditions: $1.3 \mathrm{wt} \% \mathrm{M} / \mathrm{BP} 2000$ (M: $14 \mu \mathrm{g}$-atom), additive $8.5 \mathrm{mM}$ based on cation, water $40 \mathrm{~mL}, p\left(\mathrm{H}_{2}\right) 5$ MPa, 463 K, 24 h. ${ }^{a}$ Sor: sorbitol; Man: mannitol; Xyl: xylitol; Ara: arabitol; EG: ethylene glycol; PG: propylene glycol; Others: glycerol, erythritol, hexanetetrol, sorbitan, and unidentified products containing undetected ones. ${ }^{\text {b }}$ $433 \mathrm{~K} .{ }^{c} 70 \mathrm{wt} \% \mathrm{Ni} /$ Ketjenblack EC600JD $50 \mathrm{mg}$. This catalyst is active for the conversion of cellulose. ${ }^{\mathrm{d}}$ Microcrystalline cellulose $320 \mathrm{mg} .{ }^{\mathrm{e}}$ Arabinoxylan $324 \mathrm{mg} .{ }^{\mathrm{f}}$ Sorbitol $180 \mathrm{mg} .{ }^{\mathrm{g}}$ Determined by HPLC analysis. ${ }^{\mathrm{h}}$ Based on xylan content. ${ }^{i}$ Based on arabinan content. 


\section{Figure captions}

Figure 1. Hydrolytic hydrogenation of cellulose and hemicellulose.

Figure 2. XRD patterns of silver grass samples.

Figure 3. Time course of the hydrolytic hydrogenation of silver grass-2AN.

Figure 4. Reaction pathways for the catalytic conversion of cellulose. 


\section{Figures}

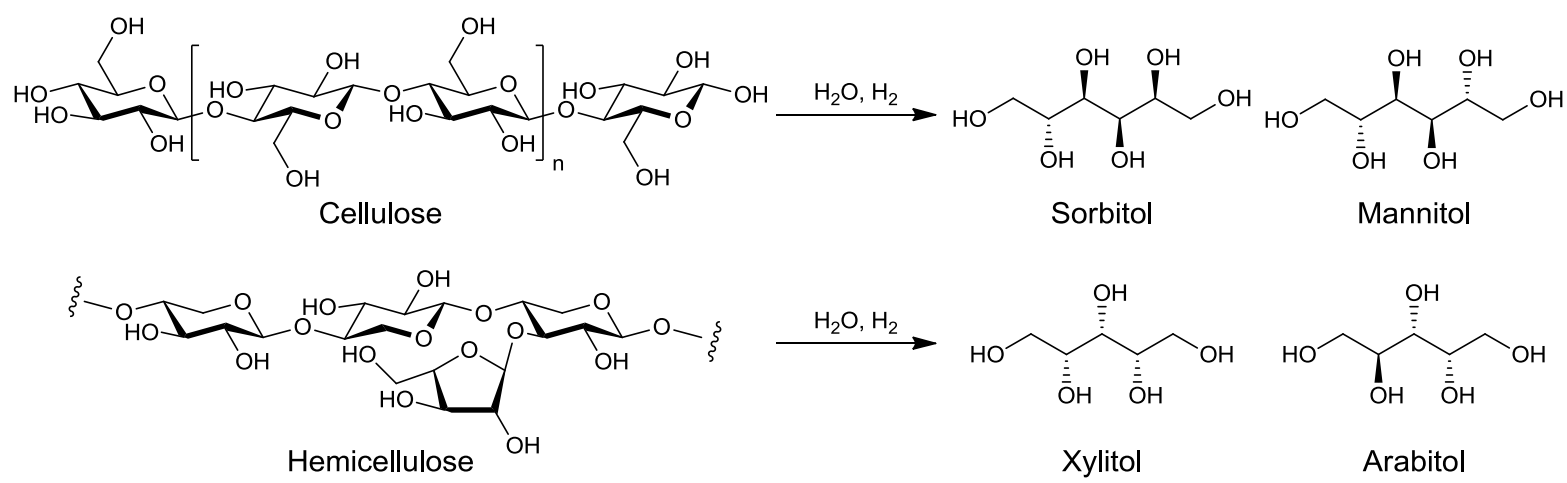

Figure 1. Hydrolytic hydrogenation of cellulose and hemicellulose.

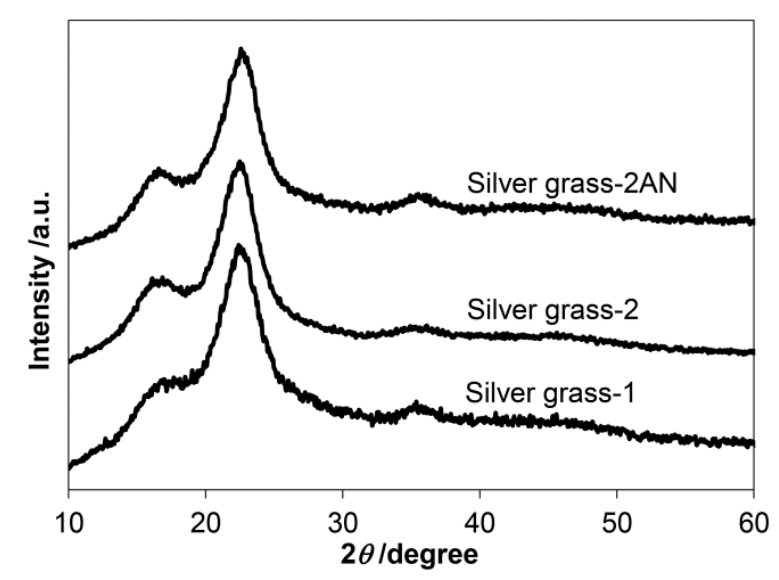

Figure 2. XRD patterns of silver grass samples.

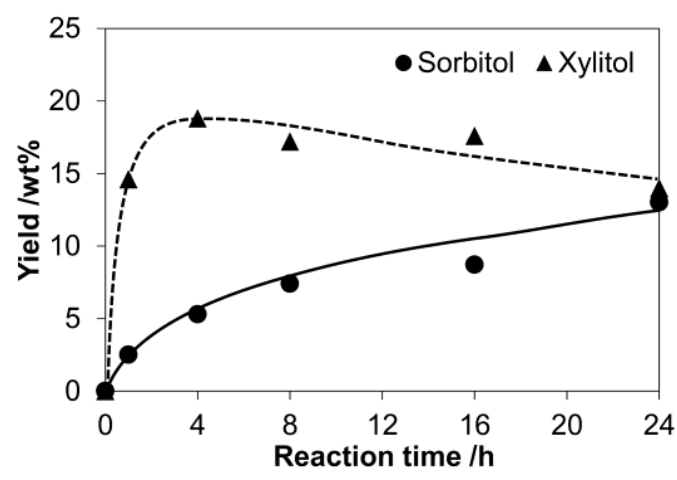

Figure 3. Time course of the hydrolytic hydrogenation of silver grass-2AN. 


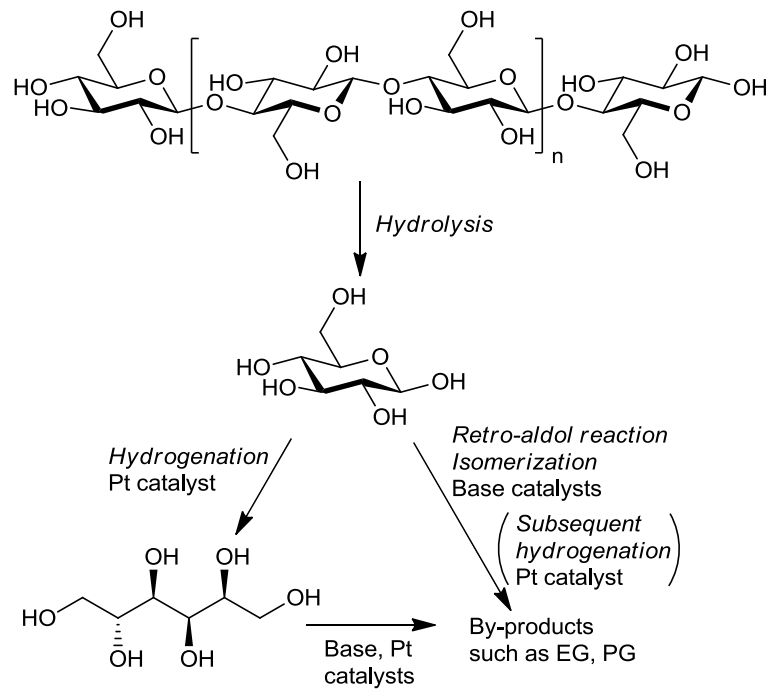

Figure 4. Reaction pathways for the catalytic conversion of cellulose. 